\title{
Conceitos PRIMEIROS DE NEOLIBERALISMO
}

\author{
Sidney Tanaka S. Matos ${ }^{1}$
}

\begin{abstract}
Resumo
Este artigo pretende apresentar as idéias fundamentais do pensamento neoliberal, por meio de uma breve reconstituição histórica que contempla sua ascensão ao poder político e o desenvolvimento das idéias de alguns de seus principais teóricos no século XX, analisando-as criticamente e buscando demonstrar as implicações políticas dessa ideologia.

Palavras-Chave: Consenso de Washington. Estado. Ideologia. Neoliberalismo.
\end{abstract}

\begin{abstract}
This article attempts to present the core ideas of neoliberal thinking through a short historical reconstitution that includes its ascent to political power and the development of the ideas of some of its main thinkers during the $20^{\text {th }}$ century, analyzing them critically and attempting to demonstrate the political implications of this ideology.

Keywords: Washington Consensus. The State. Ideology. Neoliberalism.
\end{abstract}

${ }^{1}$ Mestre em Ciências Sociais pela Universidade Estadual de Londrina.

192 • MEDIAÇÕES • v. 13, n.1-2, p. 192-213, Jan/Jun e Jul/Dez. 2008 
$\grave{A}$ s vésperas de completar seu aniversário de 30 anos de subida ao poder no Reino Unido (1979), que é o grande marco da sua ascensão política, críticas originadas dos mais diversos espectros do pensamento político e econômico mundial. Porém, fora do plano do discurso, suas idéias ainda fundamentam as políticas dos principais organismos econômicos multilaterais (FMI, OMC, Banco Mundial) e dos governos dos países de capitalismo desenvolvidos e dos chamados "países emergentes" - estes últimos tendo suas políticas condicionadas em grande parte por estes organismos multilaterais e pela influência dos governos dos países de capitalismo avançado -, demonstrando que, por trás da sua aparente crise, o neoliberalismo ainda se mantém como o principal paradigma econômico (e político) da atualidade, o que torna necessária a contínua análise de seus efeitos econômicos esuas implicações políticas como forma de entender os desdobramentos do modo de produção capitalista neste início de século XXI.

A ideologia neoliberal surge na Europa Ocidental e América do Norte no pós-II Guerra Mundial, desenvolvendo-se desde o início do século XX a partir da "Escola Austríaca", fundada por Carl Menger e continuada por Ludwig Von Mises, que formulou os postulados que caracterizam o eixo do pensamento neoliberal até os dias atuais.

Baseada na revalorização do liberalismo econômico dos séculos XVIII e XIX, esta ideologia tentaria recuperar o "sentido original do liberalismo", apontando para uma descaracterização do termo "liberal" em relação ao liberalismo clássico. Esta descaracterização seria sintoma do progressivo afastamento das sociedades ocidentais dos princípios que supostamente levaram estas sociedades a um período de melhoria sem precedentes do padrão de vida de sua população - período localizado, segundo Von Mises (1987) entre as Guerras Napoleônicas e a I Guerra Mundial, quando teria havido um "mundo pacífico de nações livres", caracterizado pela "democracia de mercado".

É importante observar a estreita relação entre o momento histórico em que esta ideologia começa a ganhar corpo e a luta política e ideológica que se acirra no imediato pós-II Guerra Mundial, com a divisão do mundo entre os blocos capitalista e socialista e o desenvolvimento da realidade política bipolar da Guerra Fria.

Sintomaticamente, o que pode ser considerado o grande marco do 
surgimento do pensamento neoliberal - a publicação do livro 0 Caminho da Servidão, de Friedrich Auguste Hayek, discípulo de Von Mises - se dá em 1944, na Grã-Bretanha. 0 livro, um violento ataque ao intervencionismo estatal nos mecanismos de mercado - denunciado como ameaça à liberdade individual, não somente econômica, mas também política, na medida em que levaria a consequências imprevistas (porém inevitáveis), como 0 crescimento da coerção administrativa arbitrária e a progressiva destruição do Estado de direito que, por sua vez, levariam à constituição de um regime totalitário - tinha como alvo o Partido Trabalhista inglês, às vésperas da eleição geral de $1945^{2}$.

Porém, nas décadas seguintes, as idéias neoliberais não obtiveram grande difusão, visto que os países de capitalismo avançado estavam atravessando a longa fase de crescimento econômico que ficou conhecida como "os trinta gloriosos" - o crescimento do PIB nos Estados Unidos e na Europa Ocidental alcançou a taxa de 5\% ao ano no período 1960-1970, segundo René Villarreal (1984), o que não resultou num ambiente muito propício às críticas neoliberais acerca dos perigos do Welfare State.

É somente a partir de 1973, quando os países de capitalismo avançado caem numa longa e profunda recessão, combinando baixas taxas de crescimento com altas taxas de inflação (como demonstram os quadros que seguem), que o pensamento neoliberal começa a se difundir com maior força (VILLARREAL, 1984, p.509). A partir daí, as idéias neoliberais passaram a ganhar terreno, com suas críticas ao poder dos sindicatos e do movimento operário em geral, que teriam corroído as bases de acumulação capitalista pelas suas pressões reivindicativas sobre os salários, por um lado, e pela sua pressão para que o Estado aumentasse os gastos sociais, por outro.

A proposta neoliberal para combater a crise era simples: a manutenção de um Estado forte o suficiente para romper o poder dos sindicatos e manter o controle monetário, mas diminuto nos gastos sociais e nas intervenções na economia. Além disso, propunham o abandono da meta do pleno emprego, para a criação de um exército de reserva de trabalhadores e reformas fiscais para incentivar os agentes

${ }^{2}$ Mais tarde, em 1947, Hayek e outros simpatizantes do neoliberalismo (entre eles Milton Friedman, Karl Popper e Ludwig Von Mises) reúnem-se na estação de esqui de Mont Pèlerin (Suíça), fundando a Mont Pèlerin Society, uma sociedade neoliberal dedicada a promover a economia de livre mercado. 
econômicos (ou seja, reduções de impostos sobre os rendimentos mais altos e sobre as rendas) (ANDERSON, 1998, p.10-11).

\section{Países Industrializados - Crescimento Econômico Anual}

\begin{tabular}{|l|c|c|}
\hline \multicolumn{1}{|c|}{ País } & $1967-1973$ & $1973-1978$ \\
\hline Inglaterra (PIB) & 3,4 & 1,1 \\
\hline Estados Unidos (PNB) & 3,5 & 2,4 \\
\hline Japão (PNB) & 10,2 & 3,7 \\
\hline França (PIB) & 5,6 & 2,9 \\
\hline Alemanha Oc. (PNB) & 5,3 & 2,0 \\
\hline OCDE $^{3}$ & 4,8 & 2,5 \\
\hline
\end{tabular}

Fonte: VILLARREAL (1984, p. 509).

\section{Países Industrializados - Inflação Anual}

\begin{tabular}{|c|c|c|c|c|c|c|c|}
\hline ANO & Inglaterra & EUA & Japão & Alemanha 0c. & França & Canadá & Itália \\
\hline 1967 & 2,5 & 2,8 & 4,0 & 1,4 & 2,7 & 3,6 & 3,7 \\
\hline 1968 & 4,7 & 4,2 & 5,3 & 2,9 & 4,5 & 4,0 & 1,4 \\
\hline 1969 & 5,4 & 5,4 & 5,2 & 1,9 & 6,4 & 4,6 & 2,6 \\
\hline 1970 & 6,4 & 5,9 & 7,7 & 3,4 & 4,8 & 3,3 & 5,0 \\
\hline 1971 & 9,4 & 4,3 & 6,1 & 5,3 & 5,5 & 2,9 & 4,8 \\
\hline 1972 & 7,1 & 3,3 & 4,5 & 5,5 & 6,2 & 4,8 & 5,7 \\
\hline 1973 & 9,2 & 6,2 & 11,7 & 6,9 & 7,3 & 7,6 & 10,8 \\
\hline 1974 & 16,0 & 11,0 & 24,5 & 7,0 & 13,7 & 10,8 & 19,1 \\
\hline 1975 & 24,2 & 9,1 & 11,8 & 6,0 & 11,8 & 10,8 & 17,0 \\
\hline 1976 & 16,5 & 5,8 & 9,3 & 4,5 & 9,6 & 7,5 & 16,8 \\
\hline 1977 & 15,9 & 6,5 & 8,1 & 3,9 & 9,4 & 8,0 & 17,0 \\
\hline 1978 & 8,3 & 7,7 & 3,8 & 2,6 & 9,1 & 9,0 & 12,1 \\
\hline 1979 & 13,4 & 11,3 & 3,6 & 4,1 & 10,7 & 9,2 & 14,7 \\
\hline 1980 & 18,0 & 13,5 & 8,0 & 5,5 & 13,3 & 10,1 & 21,2 \\
\hline 1981 & 10,9 & 10,7 & 5,1 & 6,0 & 13,8 & 13,0 & 19,3 \\
\hline
\end{tabular}

Fonte: VILLARREAL (1984, p. 509).

Anderson observa, porém, que a hegemonia neoliberal levou ainda quase uma década para se confirmar, pois, nos anos 70, a maioria dos governos da OCDE

\footnotetext{
${ }^{3}$ Composição atual da Organização para a Cooperação e Desenvolvimento Econômico (OCDE): Alemanha, Austrália, Áustria, Bélgica, Canadá, Coréia do Sul, Dinamarca, Eslováquia, Espanha, Estados Unidos, Finlândia, França, Grécia, Holanda, Hungria, Irlanda, Islândia, Itália, Japão, Luxemburgo, México, Noruega, Nova Zelândia, Polônia, Portugal, Reino Unido, República Tcheca, Suíça, Suécia e Turquia.
} 
ainda enfrentava a crise a partir da ótica keynesiana. Somente em 1979, com a eleição de Thatcher, na Inglaterra, é que assume o poder o primeiro regime de um país capitalista avançado publicamente empenhado em pôr em prática o programa neoliberal. Logo depois, assumem Reagan, nos Estados Unidos (1980), Khol, na Alemanha Ocidental (1982), Schluter, na Dinamarca (1983), e, em seguida, quase todos os países do norte da Europa Ocidental, com exceção da Suécia e da Áustria, elegem governos neoliberais.

0 governo Thatcher, segundo Anderson, foi caracterizado pela contração monetária, elevação das taxas de juros, diminuição dos impostos sobre os rendimentos altos, abolição dos controles sobre os fluxos financeiros, aumentos dos níveis de desemprego, repressão a greves (em especial o movimento mineiro), imposição de uma nova legislação anti-sindical, corte dos gastos sociais e um amplo programa de privatização.

Já Reagan, devido à própria inexistência de um Estado de bem-estar do tipo europeu nos Estados Unidos, concentrou sua política na competição militar com a União Soviética, como forma de quebrar sua economia. Internamente, Reagan também reduziu impostos em favor dos ricos, elevou as taxas de juros e reprimiu a única greve séria do período (aviação civil). A corrida armamentista criou, por outro lado, um déficit público sem precedentes.

Outros países europeus, ainda segundo Anderson, praticaram em geral um neoliberalismo mais cauteloso, mantendo a ênfase na disciplina orçamentária e nas reformas fiscais, mais do que em cortes brutais de gastos sociais ou enfrentamentos deliberados com os sindicatos. Já no sul da Europa (França, Grécia, Espanha, Portugal e Itália), observou-se a ascensão de governos de esquerda (euro-socialistas), que adotaram políticas neoliberais, com prioridade para a estabilidade monetária, a contenção do orçamento, concessões fiscais aos detentores de capital e abandono das políticas de pleno emprego.

$\mathrm{Na}$ Austrália e na Nova Zelândia, as reformas neoliberais alcançaram proporções dramáticas. Segundo Anderson, a Nova Zelândia é o exemplo mais extremo de destruição do Estado de bem-estar de todo o mundo capitalista avançado. John Gray, economista da London School of Economics e apoiador de primeira ordem da política econômica de Thatcher e, portanto, acima de qualquer suspeita de "esquerdismo", faz um relato bastante interessante do caso neozelandês em seu livro Falso Amanhecer - Os equívocos do capitalismo global. 
Gray (1999, p. 57-58) observa que imediatamente após a subida ao poder do Partido Trabalhista, em 1984, adotou-se o câmbio flutuante e o mercado foi desregulamentado, com a extinção de controles de preços, salários, taxas de juros, etc. Foram retirados subsídios à exportação e à agricultura, e a maioria das empresas estatais foi privatizada. 0 mercado de trabalho foi também desregulamentado, com a substituição do sistema de negociação coletiva nacional pelo contrato individual de trabalho e a meta do pleno emprego foi abandonada em favor da estabilidade de preços, com a criação, inclusive, de um Banco Central independente.

Ainda segundo Gray, a imposição do modelo neoliberal nos serviços públicos foi extremamente abrangente:

Os hospitais públicos foram convertidos em empresas comerciais e estimulados a competir com os fornecedores privados de assistência médica. A educação foi reestruturada, com a responsabilidade pelo fornecimento de serviços educacionais devolvida às diretorias das escolas locais. As escolas cobravam remuneração por seus serviços e precisavam complementar o orçamento com atividades comerciais. As habilitações para os benefícios previdenciários de toda espécie foram rigorosamente cortadas, e a população foi estratificada em categorias econômicas que determinavam níveis de subsídio para os serviços estatais. Todo serviço estatal foi mercantilizado e todas as funções previdenciárias do Estado foram reduzidas (GRAY, 1999, p.58).

Porém, como ressalta Chesnais (1997), a generalização dessas políticas não surge por acaso, ou como prova de sua pretensa superioridade científica ou, como diria Williamson (1992, p.48), "sabedoria convencional". Para entender a generalização destas políticas, é necessário pensar o político e o econômico agindo simultaneamente:

0 triunfo atual do "mercado" não teria sido possível sem as intervenções políticas repetidas de instâncias políticas dos Estados capitalistas mais poderosos. Por meio de uma articulação estreita entre o político e o econômico é que as condições para a emergência dos mecanismos e das configurações dominantes desse regime foram criadas (CHESNAIS, 1997, p.23-24).

A implantação das políticas neoliberais nos países de capitalismo avançado na década de 80 conseguiu controlar as taxas de inflação e recuperar a taxa de lucro das empresas - devido às derrotas impostas ao movimento sindical e ao crescimento das taxas de desemprego, criando um grande exército industrial de reserva. Porém, fracassou em restaurar as altas 
taxas de crescimento estável da economia. Segundo Anderson, esse fracasso é devido ao processo de desregulamentação financeira, fruto do abandono do Tratado de Bretton Woods pelos norte-americanos ${ }^{4}$, que criou condições muito mais propícias para a inversão especulativa do que produtiva. Por outro lado, o peso do Estado de bem-estar, ainda segundo Anderson, não diminuiu tanto quanto queriam os neoliberais, por duas razões básicas: 0 aumento dos gastos sociais com o desemprego e o aumento demográfico dos aposentados na população. Por fim, em 1991, o capitalismo avançado entra em nova crise de profunda recessão, com o crescimento da dívida pública de quase todos os países ocidentais e o endividamento privado das famílias e das empresas chegando a níveis sem precedentes desde a II Guerra Mundial.

Ou seja, mesmo os períodos de crescimento econômico são cada vez mais instáveis, e a generalização da implantação das políticas econômicas neoliberais patrocinadas pelos organismos econômicos multilaterais (FMI, Banco Mundial) e pelo governo norte-americano não conseguiram dar estabilidade às economias capitalistas avançadas ou periféricas. Assim, ainda está por se definir os limites das políticas neoliberais, pois, apesar de muitas críticas, muito pouco tem sido feito pelos organismos econômicos internacionais e pelos governos para modificar as políticas econômicas atuais.

\section{A Teoria Econômica (Política) Neoliberal}

Emseu livro O Caminho da Servidão, Hayek desenvolve um tema recorrente na literatura neoliberal que é o ataque à planificação da economia. Defendendo

\footnotetext{
${ }^{4}$ Estes acordos criaram o FMI e o Banco Mundial, além de estabelecer a paridade cambial fixa entre as principais moedas ocidentais e o ouro. Sendo o dólar a moeda mais importante, ele transformouse, na prática, na moeda internacional, visto que os acordos previam sua conversibilidade em ouro a uma taxa fixa de US\$ 35,00 a onça. Vigoraram até o início da década de 70, quando os Estados Unidos, sob a égide da crise, abandonam unilateralmente a conversibilidade entre o dólar e 0 ouro e o sistema de taxas de câmbio fixas. 0 fim do sistema monetário de Bretton Woods implicou na inexistência de uma âncora internacional de moedas - devido ao fim da paridade dólar-ouro - e, com isso, no entrelaçamento dos mercados de câmbio e financeiro. A partir daí, desenvolveuse uma crescente instabilidade nas transações econômicas internacionais, determinando uma crescente volatilidade das taxas de juros e de câmbio.
} 
a idéia de que o planejamento econômico leva inexoravelmente ao totalitarismo, faz um violento ataque às limitações impostas pelo Estado aos mecanismos de mercado, atingindo os princípios que sustentavam o Estado de Bem-Estar (ou Estado Previdenciário, como denomina o autor) que se desenvolveu na Europa Ocidental a partir da década de 30.

Para ele, as instituições políticas características do Estado de Bem-Estar progressivamente corroeriam as tradições de liberdade política características da sociedade inglesa $a^{5}$ por meio de uma "transformação de ordem psicológica" do povo, curiosamente, causada pelo próprio sucesso do liberalismo em aperfeiçoar a sociedade, que criaria um estado de espírito em que as pessoas teriam se tornado menos dispostas a tolerar "os males ainda existentes" na sociedade.

Assim, para Hayek, a transformação da "sociedade livre" em uma sociedade socialista totalitáriaéum processo político e resultado de uma "concepção errônea" da opinião pública; refletindo uma desconfiança característica do pensamento liberal em geral em relação ao comportamento político das massas; desconfiança perceptível também em Von Mises, que vê nas massas a incapacidade de raciocinar logicamente e o imediatismo que faz com que prefiram uma vantagem especial momentânea a um ganho duradouro que tenha que ser postergado (VON MISES, 1987, p.155).

0 problema desse caráter ilógico e imediatista das massas é que o remédio indicado para fugir a este futuro totalitário é justamente o sacrifício das vantagens imediatas do planejamento central da economia ${ }^{6}$. Este sacrifício teria como resultado a preservação do estímulo ao progresso social, na medida em que não se pode prever qual das numerosas maneiras de se oferecer determinado bem ou serviço será, no futuro, a mais adequada, o que torna a liberdade econômica dos agentes de mercado essencial para o processo de desenvolvimento. Assim, 0 caminho da servidão constituía-se, para Hayek, num grande alerta para o perigo

\footnotetext{
${ }^{5}$ Hayek reconhece 0 caminho da servidão como um livro político, não como um tratado científico, e tendo como público-alvo original o inglês, em especial os "socialistas de todos os partidos", constituindo-se numa "advertência a inteligentsia socialista inglesa".

${ }^{6}$ Em contraposição à idéia de igualdade econômica substantiva em que se baseia o socialismo, Von Mises também se utiliza extensivamente do argumento da renúncia provisória a um benefício imediato, por mais atraente que seja, como forma de preservação da liberdade individual. Em sua opinião, exigir benefícios econômicos imediatos é um ato de insensatez, pois isto impediria que um benefício maior pudesse ser obtido mais tarde pelo desenvolvimento "natural" das forças de mercado.
} 
que a sociedade livre estava correndo devido ao intervencionismo do "Estado previdenciário" na economia.

\section{Como se organiza a Sociedade Livre}

Baseando-se na clássica concepção liberal de sociedade como um amontoado de indivíduos perseguindo seus próprios interesses particulares, organizados em torno de um acordo voluntário e individual e relacionando-se entre si por meio do mercado, Hayek defende que seria necessário, para preservar a liberdade econômica essencial para o progresso futuro, que os agentes de mercado tivessem total liberdade para vender e comprar a qualquer preço que encontre um interessado na transação, e que todos fossem livres para produzir, vender e comprar qualquer coisa que possa ser produzida ou vendida. Seria essencial também que o acesso às diferentes ocupações fosse facultado a todos, e que a lei não tolerasse restrições a esse acesso pelo uso da força, pois qualquer tentativa de controlar preços ou quantidades de qualquer mercadoria deformaria o sistema de preços, impedindo uma efetiva coordenação dos esforços individuais, na medida em que as alterações dos preços deixariam de refletir as alterações das condições de mercado e não mais forneceriam aos indivíduos uma informação confiável para orientação de suas ações.

Assim, a base do sistema econômico ideal do neoliberalismo é a mesma da Escola Clássica, ou seja, o laissez-faire; e, sendo o acordo entre os indivíduos voluntário e individual e cada indivíduo portador de uma escala de valores particular, os consensos em torno de qualquer objetivo comum seriam apenas parciais. Esta particularidade das escalas de valores dos indivíduos, confrontada com a necessidade de elaboração de uma hierarquização dos diversos interesses que competem entre si para a convivência em sociedade, determinaria a grande diferença da forma de organização entre a sociedade livre e a sociedade socialista.

Na sociedade de planejamento central, segundo Hayek, os especialistas responsáveis pela decisão inevitavelmente imporiam sua escala de preferência à comunidade. Já na democracia de mercado, isto não ocorreria, pois o poder de decisão estaria disperso na sociedade, e os indivíduos, perseguindo cada qual seu próprio interesse e orientados pelo sistema de preços em um mercado livre, lograriam chegar à forma ótima de alocação dos recursos disponíveis, atendendo - mesmo que de forma não planejada - o interesse geral da sociedade; graças à "mão invisível do mercado", de Adam Smith. 
Assim, Hayek conclui que a democracia só seria possível numa sociedade capitalista de mercado 7 . 0 planejamento, para ele, levaria necessariamente à ditadura, pois este seria 0 instrumento mais eficaz de coerção e de imposição de ideais, sendo, pois, essencial para que o planejamento em larga escala se tornasse possível.

Indo ainda mais longe, Hayek defende que, nos regimes "totalitários", a ascensão dos "piores" ao poder seria inevitável, pois o ditador teria que se defrontar com o dilema de escolher entre o fracasso de seus planos e o desprezo à moral comum. Este dilema propiciaria a ascensão de homens inescrupulosos, que teriam menores problemas em rejeitar a moral comum em favor da realização de seus objetivos.

Nesta linha de argumentação, conclui também que grupos fortes, numerosos e de idéias homogêneas - características que possibilitam a direção unificada dos assuntos públicos - tendem a ser constituídos pelos piores elementos da sociedade. As razões para isto seriam três: 1) inferioridade intelectual - quanto mais elevada a educação e a inteligência dos indivíduos, mais se diferenciam os seus valores e opiniões e menor é a possibilidade de consenso sobre determinada hierarquia de valores; 2) população influenciável - um ditador encontraria apoio nas camadas "dóceis e simplórias", sem fortes convicções próprias, que estariam mais propensas a aceitar um sistema de valores previamente elaborado, desde que apregoado com bastante "estrépito e insistência"; 3) identidade grupal baseada numa visão maniqueísta de sociedade dividida entre o "nós" e "eles". Pode-se perceber aqui mais uma vez a desconfiança neoliberal em relação ao comportamento das massas. 0 socialismo seria, então, um fenômeno de massas, cuja legitimidade estaria assentada na manipulação das camadas sociais mais baixas da sociedade, que, como diria Von Mises, careceriam da capacidade de raciocinar logicamente.

\footnotetext{
${ }^{7}$ Partindo também da idéia da íntima ligação entre liberdade econômica e liberdade política, Friedman (1984) argumenta que a organização econômica desempenha um papel duplo na promoção de uma sociedade livre: por um lado, a liberdade econômica seria parte da liberdade entendida em sentido mais amplo, e, por outro, a liberdade econômica seria um instrumento indispensável para o obtenção da liberdade política, na medida em que interfere diretamente na concentração ou dispersão do poder. Assim, o capitalismo competitivo, promoveria a liberdade política porque separaria o poder econômico do poder político, permitindo, desse modo, a dispersão do poder na sociedade. 0 autor ressalva, porém, que é possível haver uma organização econômica fundamentalmente capitalista e uma organização política que não seja livre.
} 
Aobservância do Estado de Direito seria a característica que mais claramente distinguiria um país livre de um país submetido a um governo arbitrário. No Estado de Direito todas as ações do Estado seriam regidas por normas gerais previamente estabelecidas e divulgadas que permitiriam prever com razoável grau de certeza de que modo a autoridade usaria seus poderes coercitivos, permitindo ao indivíduo planejar suas atividades com liberdade. Já no governo arbitrário, com o governo assumindo a direção dos meios de produção, haveria o estabelecimento de distinções de mérito entre as diferentes necessidades da sociedade, e a opinião dos planejadores acabaria por determinar quais os interesses preponderantes, constituindo-se num poder autoritário.

\section{IgUALDADE LEGAL E IGUALDADE EcoNÔMICA}

Para Hayek, existe um conflito imanente entre a manutenção de um Estado de Direito e a imposição de políticas redistributivas. Para ele, a igualdade formal perante a lei entra em conflito com qualquer atividade do governo que vise a uma equiparação das condições materiais dos indivíduos, pois pressupõe o tratamento diferenciado de indivíduos legalmente iguais.

Mas, se para Hayek a desigualdade econômica seria moralmente justificável pela igualdade legal, para Von Mises ela seria até mesmo funcional, pois, por um lado, serviria de estímulo à produção: "Simplesmente pelo fato de a desigualdade da riqueza ser possível em nossa ordem social, simplesmente pelo fato de estimular a que todos produzam o máximo que possam, é que a humanidade hoje conta com toda a riqueza atual de que dispõe para consumo" (VON MISES, 1987, p. 33); e, por outro, porque propiciaria o consumo de bens de luxo, que estimularia a indústria a descobrir e introduzir novos produtos e técnicas, constituindo-se num dos fatores dinâmicos da economia e levando à elevação gradativa do padrão de vida de todos os estratos da população. Além disso, do ponto de vista moral, sendo a propriedade privada uma instituição benéfica a todos, e sendo o sacrifício por ela imposto apenas provisório e em favor do bem de toda a sociedade no futuro, na medida em que mantém as condições para o desenvolvimento constante da sociedade, ela não poderia ser considerada imoral.

\section{A Propriedade Privada}

A ideologia neoliberal considera a propriedade privada o fundamento da liberdade individual. Para Hayek, ela se constituiria nessa garantia - não só para os 
proprietários, mas também para os não-proprietários - porque a descentralização do poder sobre os meios de produção impediria o Estado de obter poder absoluto sobre os indivíduos, garantindo-lhes a possibilidade de livre escolha para seus destinos $^{8}$.

Além do aspecto da descentralização do poder apontado por Hayek, Von Mises defende sua superioridade em relação a outros sistemas de organização da economia sob o argumento - corolário da justificativa da funcionalidade da desigualdade econômica - de que no sistema capitalista os indivíduos consomem de acordo com a produtividade de seu trabalho. A existência da propriedade privada seria, assim, um incentivo para o indivíduo executar seu trabalho com maior eficiência, possibilitando alcançar a maior produção possível.

Tendo em vista a concepção recuperada aos clássicos da separação/ contraposição entre sociedade civil e Estado, a propriedade privada vai aparecer na ideologia neoliberal como um universo livre da ação do Estado, contrabalançando seu poder e impondo limites a sua "vontade autoritária", constituindo-se, assim, em instituição garantidora da manutenção da liberdade.

Assim, sendo a propriedade privada instituição garantidora da liberdade e elemento essencial no desenvolvimento econômico, ela não seria um privilégio para um indivíduo ou classe, mas sim um arranjo benéfico para a sociedade como um todo e, portanto, plenamente justificável dentro da postura de sacrifícios provisórios visando ao bem futuro da sociedade.

\section{O Estado}

$\mathrm{Na}$ ideologia neoliberal, o Estado ideal é visto como uma instituição necessária à defesa da propriedade privada; um aparelho de natureza basicamente coercitiva e com uma limitação bastante radical de suas funções: garantir a proteção à vida, à saúde, à liberdade e à propriedade privada, bem próxima da concepção lockeana do Estado (LOCKE, 1983). Os autores neoliberais vêem com temor 0 crescimento do poder estatal, considerando-o uma ameaça à economia de mercado e, consequentemente, à liberdade individual.

Assim, o papel do Estado ficaria restrito a criar e manter as condições necessárias à manutenção de um mercado concorrencial eficiente, atuando como

\footnotetext{
${ }^{8}$ Deve-se ter em mente que Hayek concebe a sociedade capitalista como um conjunto de indivíduos agindo dentro de um sistema de consenso voluntário e, por isso, o controle dos meios de produção se acharia dividido entre muitas pessoas agindo de modo independente.
} 
um árbitro e garantindo o cumprimento das leis, complementando a ação do mercado nas áreas em que este não possa ser eficiente, e fornecendo serviços que, embora sejam necessários para a sociedade, não são economicamente atraentes para os agentes de mercado.

Intervenções no mercado de bens, ou mesmo regulamentações trabalhistas ou leis de proteção aos trabalhadores nacionais (como leis de imigração, por exemplo), agrediriam a liberdade econômica e direitos fundamentais do indivíduo, afetando o sistema de preços e a produtividade e causando uma redução da oferta de bens à disposição dos indivíduos.

0 regimede governo ideal para a ideologia neoliberaléo regime democrático formal. Von Mises defende este regime a partir de uma análise racionalista: ele evitaria guerras civis, revoluções ou insurreições, que prejudicam a produção, adaptando o governo aos desejos dos governados de forma pacífica.

\section{O Monetarismo de Milton Friedman}

Apesar de o maior impacto das idéias de Milton Friedman ter se dado na década de 70, já na década de 50 é possível verificar a consolidação de seu pensamento, com o lançamento de sua versão modificada da teoria quantitativa da moeda em Chicago - em oposição a Keynes - criticando o "populismo" do governo em condições de liberdade de emissão de moeda e apregoando o controle monetário.

Esse monetarismo friedmaniano representa, como não poderia deixar de ser, uma volta ao pensamento clássico, e retoma os pressupostos da Escola Austríaca de economia como base de sua argumentação: concepção de sociedade como amontoado de indivíduos livres e suas vontades individuais com ênfase na liberdade individual, divisão do trabalho baseada na cooperação voluntária de indivíduos livres ${ }^{9}$, oposição entre sociedade civil (mercado) e Estado (governo), defesa da limitação dos poderes do Estado como garantia de preservação da liberdade

\footnotetext{
${ }^{9} 0$ esquema básico de livre mercado de Friedman é representado por um mundo idílico onde pequenos produtores trocam bens e serviços produzidos e que têm a opção de produção para 0 autoconsumo (sendo voluntária, portanto, sua participação na troca). Este esquema seria válido mesmo no mercado moderno, caracterizado pelas empresas e pelo uso do dinheiro, pois a característica central da técnica de mercado para obter a cooperação voluntária estaria completamente representada na simples economia de troca.
} 
individual, defesa do livre mercado ${ }^{10}$ como instrumento de descentralização de poder e defesa da liberdade, e ataque ao Welfare State são básicos no pensamento de Friedman.

Para Friedman, tarifas e outras restrições ao comércio internacional fornecem aos indivíduos um incentivo para 0 uso inconveniente e inadequado dos recursos e distorce 0 investimento das novas poupanças, deformando o sistema de preços. Visando a evitar tal inconveniente, o autor aconselha que o governo restrinja sua ação ao fornecimento de uma estrutura monetária estável à economia - como parte da função de propiciar uma estrutura legal estável.

Argumentando que as áreas mais importantes da política governamental relevantes para a estabilidade econômica são a política monetária e a política fiscal, pretende conciliar este importante papel do governo - limitando ao mesmo tempo o seu poder - propondo o estabelecimento de uma legislação de normas para a direção da política monetária que teria como efeito permitir ao público exercer o controle da política monetária por meio das autoridades políticas e, ao mesmo tempo evitar que a política monetária fosse vítima dos "caprichos das autoridades políticas" ${ }^{\prime 1}$.

Com efeito, acreditando que a inflação é um fenômeno essencialmente monetário, Friedman defende que todo aumento de oferta monetária tem como resultado o aumento da taxa de inflação. Políticas monetárias expansionistas com a intenção de crescimento econômico e criação de empregos seriam, portanto, ineficazes e teriam como resultado somente o aumento da taxa de inflação.

Isto se deve à crença na Teoria das Expectativas Racionais, que supõem que os agentes econômicos têm pleno conhecimento do impacto das políticas econômicas do Estado, formando as mesmas expectativas, baseadas em um pensamento racional e maximizador de lucros, que levaria a um ajuste automático dos preços até o novo ponto de equilibrio, tornando sem efeito a longo prazo as políticas monetárias governamentais.

\footnotetext{
${ }^{10}$ Tendo como pressuposto o mercado em concorrência perfeita, no qual nenhum participante seria capaz de determinar os termos em que os outros participantes teriam acesso a empregos ou mercadorias e todos considerariam os preços como dados pelo mercado, sendo que nenhum indivíduo poderia, por si só, ter mais do que uma influência negligenciável sobre o preço (embora todos os participantes juntos determinem o preço por meio do efeito combinado de suas ações, que constituem o sistema de preços).

${ }^{11}$ Para Friedman, a Grande Depressão teria sido causada por ação "inepta" do Federal Reserve System na condução da política monetária (FRIEDMAN, 1984, p. 43).
} 
Assim, para controlar a inflação, considerada por ele o principal problema econômico, o governo deveria se restringir ao cumprimento de uma norma que estabeleceria que a oferta monetária cresceria a uma taxa constante composta pelo crescimento do produto mais o crescimento "desejável" do nível de preços no mercado, abrindo mão de políticas econômicas ineficazes e limitando gastos, que teriam como resultado somente o desequilíbrio da economia.

Da mesma forma, sendo o mercado o instrumento mais capaz de alocar os recursos da sociedade de maneira eficiente, o Estado deveria abrir mão de uma maior capacidade extrativa dos recursos da sociedade, limitando impostos. Pelo mesmo raciocínio, deveriam também ser eliminados os controles de preços e salários e todo o tipo de regulamentação do mercado (inclusive educação e saúde).

No campo da política externa, assim como os representantes da Escola Austríaca, Friedman defende a total liberdade de comércio internacional, baseada na visão de equilíbrio nas transações comerciais da Lei das Vantagens Comparativas de Ricardo ${ }^{12}$. A estabilidade econômica dentro deste livre-mercado mundial, porém, estabelece a necessidade de equilíbrio no balanço de pagamentos, ou seja, o total de pagamentos tem que igualar o total de recebimentos. Há, segundo o autor, quatro modos de ajuste do balanço de pagamentos: 1) utilização das reservas; 2) redução dos preços internos de forma a deixar as mercadorias mais atrativas para comércio externo; 3) aumento da taxa de câmbio; 4) controle do câmbio - controles governamentais diretos ou interferências com o comércio),

\footnotetext{
${ }^{12}$ David Ricardo defende, em "Princípios de Economia Política e Tributação", que, em um sistema comercial perfeitamente livre, cada país investiria seu capital e seu trabalho no setor da economia que lhe fosse mais vantajoso. Assim, no exemplo de Ricardo, se Portugal utiliza 80 homens/ano para produção de vinhos e 90 homens/ano para produção de tecidos, enquanto a Inglaterra utiliza 120 homens/ano para produção de vinho e 100 homens/ano para a produção de tecidos, seria vantajoso para a Inglaterra importar vinho português em troca do tecido inglês, enquanto para Portugal, seria vantajoso importar tecido inglês em troca do vinho português, mesmo utilizando menos homens/ano para a produção de tecidos (90) do que a Inglaterra (100), pois assim poderia investir o capital e o trabalho no setor mais vantajoso economicamente. Ricardo propunha, assim, uma especialização dos países na produção dos produtos que possam ser produzidos com maior eficiência dentro de seu território, com a defesa implícita do livre comércio para satisfazer as necessidades em produtos que não seriam produzidos nacionalmente. Isto implicaria na concentração da produção de produtos de maior valor agregado nos países de capitalismo desenvolvido, cabendo aos países periféricos a produção de matérias-primas e produtos manufaturados de menor valor agregado. Ver Ricardo (1982).
} 
- criticado por Friedman e considerado "o mais destrutivo para uma sociedade livre") (FRIEDMAN, 1984, p.64-66).

Para Friedman, existem somente dois métodos consistentes com 0 mercado livre para o equilíbrio no balanço de pagamentos externos: 1) padrãoouro automático (não factível, nem desejável, segundo ele); e 2) taxas de câmbio livremente flutuantes sem intervenção governamental; este último, recomendado como 0 método capaz de fornecer resposta automática e efetiva às mudanças nas condições que afetam o mercado internacional.

\section{Os anos 90 e o Consenso de Washington}

Já no final da década de 80 e principalmente nos anos 90, a doutrina neoliberal passa a ser sintetizada nos pressupostos do chamado "Consenso de Washington". Esta conhecida denominação, atribuída ao economista John Williamson, é o resultado de um encontro acadêmico (e sem caráter deliberativo) realizado em Washington em novembro de 1989, no think tank Institute for International Economics sob o título "Latin American Adjustment: How Much Has Happened?".

Neste encontro, funcionários do governo norte-americano e de organismos financeiros internacionais (FMI, Banco Mundial e BID), além de diversos economistas latino-americanos, fizeram uma avaliação extremamente positiva a respeito das reformas econômicas empreendidas na América Latina, baseadas nas políticas de caráter neoliberal recomendadas pelo governo norte-americano por meio destas instituições como condição para conceder cooperação financeira externa, bilateral ou multilateral; reunindo elementos até então esparsos em um único corpo teórico, que se tornou o mais novo paradigma da política econômica neoliberal.

0 "Consenso" pode ser resumido em um conjunto de dez recomendações de caráter liberalizante da economia: 1) disciplina fiscal, 2) reorientação das prioridades de gastos públicos para áreas denominadas pelo autor como "politicamente sensíveis" (educação, saúde, infra-estrutura), 3) reforma fiscal, 4) liberalização de financiamento visando à determinação das taxas de juros pelo mercado, 5) unificação das taxas de câmbio em nível competitivo, 6) liberalização comercial, 7) liberalização do investimento externo direto, 8) privatização, 9) desregulamentação de mercado e 10) proteção de direitos de propriedade (WILLIAMSON, 1990). 
Esta simples enumeração revela sua natureza essencialmente ligada aos preceitos da ideologia neoliberal, principalmente no tocante à liberalização comercial e à estabilização econômica (incluindo a reforma do Estado).

Estas políticas, seguindo a mesma tradição das formas de ideologia neoliberal anteriores a elas, apresentadas com uma roupagem de neutralidade científica desinteressada ou mesmo expressões puras de bom senso econômico e exportadas para o mundo pela influência norte-americana, não passam, como observa Przeworski, de "uma mistura de dados empíricos, argumentos a partir de princípios primeiros, interesse próprio e wishful thinking" (PRZEWORSKI, 1993), que visariam a preparar o mercado para ingressar em uma nova fase de desenvolvimento do capitalismo que, inexoravelmente, abarcaria a economia planetária de forma mais ou menos traumática, de acordo com a observância de suas exigências. Essa nova fase seria caracterizada pela extinção das fronteiras econômicas, resultando num mundo unificado em torno do livre mercado; um mundo de competição e integração, não só econômica, mas também cultural, por meio do desenvolvimento das tecnologias de comunicação.

\section{A Recusa à Política}

A contraposição radical entre sociedade civil (representada pelo mercado) e Estado na ideologia neoliberal - considerando a sociedade civil a esfera da liberdade - tem como resultado o desprezo dos neoliberais pela atividade política.

A questão da concentração do poder nas mãos do Estado e seus efeitos na liberdade individual é a mais comumente esgrimida na desconfiança em relação à atividade política. Hayek argumenta que a concentração do poder sobre os meios de produção nas mãos do Estado o levaria a ter poder absoluto sobre os indivíduos, porque a interdependência dos fenômenos econômicos tornaria difícil limitar 0 planejamento, impedindo o livre funcionamento do mercado.

Assim, nas sociedades de planejamento central, as questões econômica e social se tornariam indistintas da questão política, levando à necessidade de atuação de um poder discricionário por parte do planejador; ao contrário do Sistema de Mercado, no qual seria permitido às forças econômicas atuar de forma independente em relação à política do governo, e o poder econômico poderia ser usado de maneira independente do controle governamental, tornando possível a descentralização do poder. 
Para agravar o temor dessa concentração do poder nas mãos dos planejadores do Estado, neoliberais concebem a atividade política como uma atividade em geral demagógica, contrapondo o conhecimento de fundo racional representado pelo liberalismo ${ }^{13}$ aos slogans e mentiras utilizadas pelos políticos antiliberais para obtenção do apoio das massas. As atividades políticas antiliberais seriam, assim, motivadas pela defesa de interesses particularistas que acabariam por destruir a sociedade.

Deve-se lembrar também que Hayek vê a tendência de ascensão dos "piores" ao controle do Estado nas sociedades totalitárias, isto porque, como foi visto, os "piores" teriam menos escrúpulos em rejeitar a moral comum em favor da realização de seus objetivos. É de se esperar que o mesmo deva acontecer, portanto, em qualquer sociedade que não conte com a limitação do poder do Estado via mercado, o que torna essa tendência inerente à atividade política.

Além disso, como coloca Von Mises, para os neoliberais, não há o antagonismo de interesses entre as diferentes classes sociais de uma sociedade baseada na propriedade privada, pois, segundo ele, o aumento do capital total faz aumentar a renda dos capitalistas e senhores de terra de modo absoluto, e a dos trabalhadores, de modo absoluto e relativo. Portanto, o liberalismo não seria uma ideologia defendendo prerrogativas e privilégios especiais porque a propriedade privada dos meios de produção não seria um privilégio do capitalista, mas uma instituição que agiria no interesse de toda a sociedade e, consequentemente, benéfica a todos.

Visto dessa forma, o neoliberalismo seria nada mais, nada menos, que a pura expressão de uma verdade científica e representante dos interesses de toda a sociedade; acima, portanto, dos interesses particularistas defendidos pelos antiliberais através de sua atividade política.

\section{O Racionalismo}

É importante notar que toda a argumentação da ideologia neoliberal é feita em torno de um ideal racionalista. Esta postura racional seria a essência da doutrina liberal, segundo seus autores; sendo o seu oposto - o Estado de economia planificada - classificado como erro, logro ou mesmo doença.

\footnotetext{
${ }^{13}$ Para Von Mises, a ideologia política do liberalismo originou-se de um sistema de idéias fundamentais desenvolvidas como teoria científica, e, portanto, sem significação política. Ao contrário, os direitos e privilégios especiais defendidos pelos antiliberais materializavam-se, desde 0 início, nas instituições sociais existentes e seriam, pois, demagógicas (VON MISES, 1987, p.159).
} 
Basta relembrar a tese da "transformação psicológica das massas" argumentada por Hayek como justificativa para a progressiva transformação da economia de mercado no "Estado Previdenciário"; uma transformação de caráter não racional, que se reforça em sua argumentação sobre a inferioridade intelectual e o caráter influenciável das massas.

Por outro lado, a ação racional no sistema liberal é identificada na "política dos sacrifícios provisórios" - na qual haveria uma renúncia provisória a determinados benefícios imediatos visando a permitir um benefício maior no futuro, de acordo com o desenvolvimento natural das forças de mercado. Há ainda a argumentação de caráter materialista, especialmente em Von Mises, como no seguinte trecho de seu livro O liberalismo segundo a tradição clássica:

Nós, liberais, não afirmamos que Deus ou a natureza tenham destinado à liberdade todos os homens, porque não nos instruímos pelos desígnios de Deus e da natureza, e evitamos, em princípio, colocar Deus e a natureza nas discussões sobre questões humanas. 0 que afirmamos é que somente um sistema baseado na liberdade para todos os trabalhadores garante a maior produtividade do trabalho humano e é, por conseguinte, de interesse de todos os habitantes da terra (VON MISES, 1987, p. 25).

0 mesmo se pode dizer em seu posicionamento em relação à guerra, no qual argumenta que o liberalismo é um sistema que zela pela paz porque a guerra é prejudicial à divisão do trabalho e ao desenvolvimento. 0 mesmo argumento é utilizado para justificar a defesa do governo democrático como forma de manutenção da paz e da produção.

Esta argumentação eleva o discurso neoliberal ao status de uma escolha de bom senso; bom senso alicerçado em argumentos racionais e facilmente constatáveis. Isto equivale a dizer que o neoliberalismo estaria, portanto, acima da mera disputa política e ideológica; e acima também de interesses particularistas, recuperando mais uma vez um aspecto fundamental da ideologia burguesa: tomar para si a identidade de classe social portadora de interesses universais.

0 que fica claro neste retrospecto do neoliberalismo é que houve a permanência da mesma linha de recuperação dos pressupostos do liberalismo clássico, com uma grande ênfase na identificação dessa ideologia com 0 racionalismo e com a ciência.

É interessante notar também um progressivo afastamento da política do foco de atenção dos pensadores neoliberais, embora se mantenha a linha de argumentação na questão da dispersão do poder engendrada pelos mecanismos 
do mercado e, portanto, sua estreita ligação com a constituição de regimes democráticos.

Porém, se na Escola Austríaca é possível notar a ênfase na militância ideológica, com uma preocupação mais ostensiva no que se refere à questão dos perigos da transformação do "Estado democrático" engendrada pelo planejamento econômico (devido até mesmo à conjuntura histórica em que este pensamento se desenvolve, principalmente em se tratando de Hayek e seu 0 Caminho da Servidão, no imediato pós-II Guerra Mundial); no pensamento de Friedman, esta preocupação, embora subjacente, torna-se menos enfática. Persiste a defesa dos fundamentos do liberalismo e toda uma argumentação teórica em torno da oposição sociedade civil-Estado; porém, fica bem claro um deslocamento do foco de preocupação para a questão monetária e, portanto, um direcionamento do debate ideológico para um campo supostamente técnico, em contraposição ao político $^{14}$. Vale ressaltar que Friedman lançou sua versão da Teoria Quantitativa da Moeda na década de 50, mas esta vai ter seu maior impacto exatamente na década de 70, quando o capital tenta dar conta da crise do modelo econômico do pós-II Guerra Mundial, que então se tornava cada vez mais evidente.

A forma assumida pelo pensamento neoliberal nos anos 90 - 0 "Consenso de Washington" - acentua ainda mais essa tendência, assumindo a forma de um receituário essencialmente técnico que uniformiza todo o mundo dentro de uma visão de mercado mundial, que se coaduna com a inflexão dos fluxos monetários na década de 80 e a "globalização" da economia.

Nota-se, portanto, que o desenvolvimento do pensamento neoliberal não pode ser entendido fora do cenário mais amplo das transformações políticoeconômicas da segunda metade do século XX.

Não se pretende sugerir aqui que tenha havido um concreto afastamento da política - é claro que toda a proposta econômica neoliberal está inserida dentro de um projeto político de uma classe (ou conjunto de classes que compõem o bloco no poder) e somente pode ser compreendido enquanto tal. Porém, a forma como ele é apresentado dentro da luta ideológica (tomada enquanto um dos aspectos

\footnotetext{
${ }^{14}$ É lícito lembrar que o próprio Hayek foi defensor da idéia de uma economia positiva, que acentuaria o caráter técnico científico da disciplina. 0 fato do debate ideológico ter sido canalizado para o discurso técnico não significa, porém, que o neoliberalismo seja uma vertente "politicamente neutra" do pensamento econômico, pois delineia um projeto político que representa os interesses do capital no que diz respeito a redução de direitos sociais e trabalhistas, maior liberdade para movimentação do capital, desregulamentação de mercados, etc.
} 
da luta de classes) desfoca este aspecto de projeto político geral da burguesia pela progressiva ênfase na abstração técnica que impõe a imagem da fria verdade científica e naturaliza o modo de produção capitalista.

Nessa mesma linha de desfocamento do processo político, é interessante notar também que, se por um lado a ideologia neoliberal se apresenta como defensora da democracia representativa e do Estado de Direito como instrumentos de preservação de uma sociedade livre; por outro, carrega em seu bojo uma profunda desconfiança (e poderia se dizer até mesmo temor) em relação à participação popular no processo democrático burguês e uma visão - baseada na rígida separação entre Estado e sociedade civil - de ação política como ação do Estado e, consequentemente, uma ameaça potencial à sociedade livre.

Além disso, descaracteriza qualquer tipo de ação coletiva que se exerça fora dos rígidos limites da democracia representativa (que por si só já inspira um certo temor). Isto é particularmente evidente quando os neoliberais abordam a ação sindical, apresentada sempre como ação corporativista e nociva ao interesse da sociedade em geral.

Este desfocamento do caráter político do projeto neoliberal disfarça, então, o que é essencial para a compreensão de seu projeto político: a ideologia neoliberal não defende o fim da intervenção do Estado na economia; defende sim, o redirecionamento da ação do Estado de forma a garantir a reprodução das relações de produção capitalistas. Não se sugere aqui, no entanto, que este processo de mascaramento da realidade se dê de forma premeditada. A ideologia, como observa Poulantzas, reflete a maneira como os agentes de uma formação social vivem suas condições sociais de existência e as relações dos agentes com essas condições, fixando em um universo relativamente coerente uma relação real e também uma relação imaginária (POULANTZAS, 1972, p.264).

É claro que a conformação concreta que tomaráo Estado em cada formação social em particular não será aquela conformação "pura" defendida pela ideologia dominante (neste caso em particular, o neoliberalismo), pois o Estado é, como coloca Poulantzas (1972), a instituição que condensa as contradições da sociedade - produto da sociedade em uma determinada etapa de seu desenvolvimento e, portanto, fruto de uma determinada relação de forças entre as classes e frações de classe em luta constante. 


\section{REFERÊNCIAS}

ANDERSON, Perry. Balanço do neoliberalismo. In: SADER, E., GENTILI, P., Pósneoliberalismo: as políticas sociais e o Estado democrático. Rio de Janeiro: Paz e Terra, 1998.

CHESNAIS, François. A emergência de um regime de acumulação mundial predominantemente financeiro. Praga - Estudos Marxistas n ${ }^{\circ} 3$. São Paulo, set. 1997.

FRIEDMAN, Milton. Capitalismo e liberdade. São Paulo: Abril Cultural, 1984. (Coleção Os Economistas).

GRAY, John. Falso Amanhecer: os equívocos do capitalismo global. Rio de Janeiro: Record, 1999.

HAYEK, Friedrich A. O caminho da servidão. Rio de Janeiro: Expressão e Cultura/ Instituto Liberal, 1987.

LOCKE, John. Segundo tratado sobre o governo. São Paulo: Abril Cultural, 1983. (Col. Os Pensadores).

POULANTZAS, Nicos. Poder político y clases sociales en el estado capitalista. México DF: Siglo Veintiuno Editores, 1972.

PRZEWORSKI, Adam. A falácia neoliberal. Lua Nova, n. 28/29. São Paulo, 1993.

RICARDO, David. Princípios de economia política e tributação. São Paulo: Abril Cultural, 1982. (Coleção Os Economistas).

VILLARREAL, Rene. A contra-revolução monetarista: Teoria, política e ideologia do neoliberalismo. Rio de Janeiro: Record, 1984.

VON MISES, Ludwig. Liberalismo segundo a tradição clássica. Rio de Janeiro: José Olympio: Instituto Liberal, 1987.

WILLIAMSON, John. Reformas políticas na América Latina na década de 80. Revista de Economia e Política, vol.12 nº 1 (45), São Paulo, jan.-mar., 1992.

What Washington means by policy reform. In: Latin american adjustment: how much has happend? Washington, D.C.: Institute for International Economics, 1990. 